\title{
SUSTENTABILIDADE EM SISTEMAS AGROINDUSTRIAIS: UM ESTUDO MULTICASOS DA CARNE BOVINA DE MATO GROSSO DO SUL, BRASIL
}

\author{
Sustainability in Agroindustrial Systems: a Multicase Study in Beef from Mato Grosso do Sul, Brazil
}

\section{RESUMO}

No artigo, discute-se o tema da sustentabilidade em se tratando da visão de Sistemas Agroindustriais (SAG). Para tanto, parte-se de um modelo de análise para SAG’s sustentáveis. A Nova Economia Institucional, especificamente Economia dos Custos de Transação, é o arcabouço teórico da pesquisa. Surgem pressupostos e hipóteses, que são avaliados, por meio de um estudo multicasos sobre a sustentabilidade da transação entre produtor e indústria no SAG da carne bovina do Mato Grosso do Sul. Foram escolhidos casos relevantes para a temática, a saber: Associação Sul-mato-grossense dos Produtores de Novilho Precoce, Programa Boas Práticas Agrícolas - Embrapa bovinos de corte e Associação Brasileira de Pecuária Orgânica. Em suma, a análise dos casos permitiu a caracterização destes SAG's e a identificação dos riscos associados à captura de valor gerado pelo investimento em ativos específicos dedicados à sustentabilidade. Ainda, sugere-se um conjunto de hipóteses a serem testadas e validadas em pesquisas futuras acerca da eficiência e estabilidade de SAG's sustentáveis.

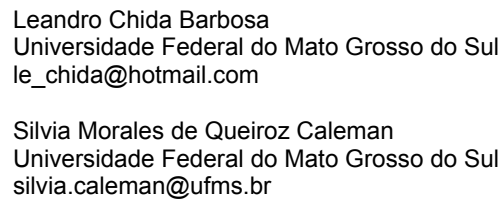

\begin{abstract}
This article discusses the theme of sustainability from the point-of-view of Agroindustrial Systems (AGSs). For this, we used an analysis model for sustainable AGSs. The New Institutional Economy, specifically the Transition Costs Economy, is the theoretical framework of the research. Presuppositions and hypothesis are evaluated by means of a multicase study on the sustainability of the transaction between the producer and the industry within the AGS of beef from Mato Grosso do Sul, Brazil. Cases relevant to the theme were chosen: Mato Grosso do Sul Association of the producers of precocious calf, Good agricultural practices program EMBRAPA cattle, and Brazilian Association of Organic Livestock. In short, the analyses of the cases allowed for the characterization of these AGSs and the identification of risks associated to capturing the value generated by the investment in specific assets dedicated to sustainability. Furthermore, we suggest a set of hypotheses to be tested and validated in future researches regarding the efficiency and stability of sustainable AGSs.
\end{abstract}

Palavras-chave: Gestão Ambiental; Agroindústria; Nova Economia Institucional; Economia dos Custos de Transação.

Keywords: Environment; Agroindustry; New Institutional Economy; Transaction Costs Economy.

\section{INTRODUÇÃO}

O tema da sustentabilidade é de grande apelo na atualidade, contudo, apresenta questões e dificuldades na busca por um consenso, motivo pelo qual as pessoas pensam saber o significado da palavra sustentabilidade, mas a definem de diversas maneiras, não havendo unanimidade sobre seu significado apesar de existir ampla utilização do termo (BARBIERI; CAJAZEIRA, 2009; ELKINGTON, 2001; KIDD, 1992). Pergunte-se: o que é sustentabilidade? E perceba a dificuldade de balizar uma resposta.

Nas empresas, a matéria ganha o nome de sustentabilidade empresarial e a questão ganha em complexidade (ARAÚJO; MENDONÇA, 2009). Às vezes denomina-se empresa sustentável aquela que sobrevive, no mercado, por longo prazo, outros traduzem como Responsabilidade Social Empresarial e há os que incluem resultados econômicos, ambientais e sociais, e o que se nota é a obscuridade sobre o que a constitui e como operacionaliza-la (MARREWIJK, 2003; FABER; JONAS; ANGELEN, 2005).

Cunha et al. (2011) e Caleman et al. (2013) atribuem essa dificuldade à complexidade do termo "sustentabilidade", que agrega dimensões socioambientaiseconômicas numa dependência mútua, além da difícil delimitação espacial do conceito, decorrendo disso, um tratamento diminuto e ineficaz, focado nas ações 
particulares das organizações publicas e privadas e dos cidadãos comuns.

Nos negócios agroalimentares a sustentabilidade focada nas práticas individuais, nos métodos de cultivo e de processamento pode ter sido relevante na era da industrialização agrícola, mas para enfrentar os novos desafios ambientais, sociais e econômicos, é necessária uma abordagem de caráter sistêmico para o agronegócio (IKERD, 1993).

Todavia, se já é complexo encontrar denominador comum para ações localizadas em uma empresa, como encontrar soluções sistemáticas, ou, dentro de um sistema produtivo, onde os interesses podem ser diversos e conflituosos?

Caleman et al. (2013) observam que o tema da sustentabilidade na produção de fibras, alimentos e bioenergia carece ser pensado em uma lógica que se conecte à visão de Sistemas Agroindustriais (SAG's) e os aspectos que tratam da coordenação dos SAG's ganham relevância, tanto teórica como prática, no sentido de equacionar os interesses dentro de um sistema rumo à sustentabilidade.

Além disso, medidas são tomadas por criadores de gado que acreditam na possibilidade de rentabilidade da atividade com preservação do meio ambiente e respeito aos aspectos sociais (WWF-BRASIL, 2012). O Mato Grosso do Sul é um estado pioneiro em relação a ações que cercam o tema da sustentabilidade nos sistemas da carne bovina, sendo vitrine para o Brasil e para outros países, quando se trata do assunto ganhando destaque em mesas de discussão sobre sistemas produtivos sustentáveis.

Nesse sentido, este artigo tem o seguinte problema de pesquisa: Como é tratada a sustentabilidade no SAG da carne bovina de Mato Grosso do Sul (MS), com vistas a um modelo analítico de Sistemas Agroindustriais sustentáveis? Como objetivos propõem-se discutir um modelo analítico de SAG's sustentáveis e identificar como é tratado o tema da sustentabilidade no SAG da carne bovina de MS analisando os aspectos institucionais e de coordenação, expondo variáveis e hipóteses para validação em uma agenda futura de pesquisa.

\section{PROCEDIMENTOS METODOLÓGICOS}

Esta pesquisa possui natureza exploratória, sendo caracterizada como descritiva e analítica (CRESWELL, 2010). Trata-se, portanto, de um ensaio qualitativo que apresenta como procedimento de pesquisa estudos de caso (YIN, 2010). A partir do referencial teórico e de pesquisa bibliográfica, identifica-se um modelo de análise de sistemas agroindustriais sustentáveis, desenvolvendose, posteriormente, estudos de caso para a proposição de variáveis e hipóteses que poderão ser operacionalizadas em estudos futuros para a análise da eficiência e estabilidade de sistemas agroindustriais sustentáveis. Eisenhardt (1989) advoga que o procedimento de estudos de casos é apropriado para a pesquisa de novos tópicos, sendo inclusive indicado para o desenvolvimento de teorias ("ground theory building") e, para tanto, uma das etapas envolve a proposição de hipóteses após a análise cruzada dos casos.

Os casos seguem uma lógica de replicação contrastante, ou seja, há tentativa de reproduzir resultados diferentes e previsíveis pelo modelo teórico proposto (replicação teórica) (YIN, 2010). Os casos selecionados são: i) Associação Sul-mato-grossense de Produtores de Novilho Precoce (ASPNP); ii) Programa Boas Práticas Agrícolas (BPA) da Embrapa gado de corte e iii) Associação Brasileira de Pecuária Orgânica (ABPO).

Foram aplicadas entrevistas semiestruturadas com atores chave dos casos, como presidentes das associações, diretores, coordenadores de programas e técnicos responsáveis por projetos de sustentabilidade, bem como feita análise de documentos disponibilizados pelos mesmos. A análise do discurso foi a técnica utilizada para tratamento dos dados. Para fins metodológicos, foi considerada apenas uma secção do SAG da carne bovina de MS para investigação, qual seja, a transação entre produtores e a indústria de abate e processamento.

Com base em Bulgacov (1998), identificam-se dois níveis de análise: i) o padrão das transações entre os agentes econômicos e ii) análise estruturada da organização e sua inter-relação com o ambiente institucional. Para tanto, considera-se um conjunto de categorias analíticas: i) investimentos em ativos específicos dedicados à sustentabilidade; ii) mecanismos de coordenação (vertical e horizontal) das transações sustentáveis; iii) incentivos gerados em prol da sustentabilidade e iv) instituições e organizações envolvidas na coordenação de uma transação sustentável. Uma última etapa da pesquisa envolve a análise cruzada dos casos. Nesse sentido, faz-se uma abordagem comparando os resultados dos casos.

\section{REFERENCIAL TEÓRICO}

Tema polêmico, pecuária e sustentabilidade tem sido objeto de pesquisas. Alguns estudos focam o sistema de produção integrada lavoura-pecuária como alternativa

Organizações Rurais \& Agroindustriais, Lavras, v. 18, n. 4, p. 315-331, 2016 
sustentável para a criação de ruminantes (MACEDO, 2009). Esses autores constam que técnicas de integração possibilitam o uso intensivo do solo com critérios de manejo e conservação da terra e da água, tornando-se um caminho para recuperação de pastagens degradadas e redução da pressão sobre o desmatamento.

Araújo e Mendonça (2009) e Caridade (2011) analisam a implantação de normas de sustentabilidade em empresas frigoríficas, bem como sua relação com as finanças corporativas. Pesquisas também exploram a criação e utilização de índices e metodologias para avaliação da sustentabilidade nos sistemas de produção da bovinocultura de corte em seus resultados econômicos, ambientais e sociais (COSTA et al., 2008; SPECHT et al., 2012).

Steiner et al. (2014) apresentam conhecimentos e ferramentas para o aumento da resiliência ambiental da produção do gado de corte nas planícies norte-americanas. Hafla et al. (2013) esclarecem a produção de carne bovina orgânica nos Estados Unidos, suas regras, formas de manejo, benefícios e comparações com a produção não orgânica, bem como a viabilidade econômica, ambiental e social, além de observarem o papel que o preço prêmio pago pelo consumidor tem para a continuidade desse tipo de atividade.

Hafla et al. (2013) e Steiner et al. (2014) advertem sobre a importância das instituições e do envolvimento de todos os agentes do sistema para a continuidade das ações sustentáveis, porém, não se aprofundam nesse debate. Farahnaz et al. (2014) alertam para a importância de se definir as questões de sustentabilidade, a partir de uma perspectiva do sistema produtivo como um todo, ou seja, como surgem e como variam de acordo com os interesses dos agentes.

Ao mesmo tempo, Caleman et al. (2013) observam que o tema da sustentabilidade na produção de fibras, alimentos e bioenergia carece ser pensado em uma lógica que se conecte à visão de Sistemas Agroindustriais (SAG's).

Goldberg redefiniu o conceito de agronegócio ${ }^{1}$ em 1968, utilizando a noção de Commodity System Approach (CSA): engloba todos os participantes envolvidos na produção processamento e marketing de um produto específico. Inclui o suprimento das fazendas,

${ }^{1}$ Por definição, o agronegócio é a soma total das operações envolvidas na fabricação e distribuição de suprimentos agrícolas, das operações de produção nas unidades agrícolas, do armazenamento, processamento e distribuição dos produtos agrícolas e itens fabricados a partir deles (DAVIS; GOLDBERG, 1957, p. 2). as unidades agrícolas, o armazenamento, o processamento e a distribuição em um fluxo, desde o insumo até o consumidor final. Abarca também as instituições que afetam e coordenam os estágios sucessivos do fluxo do produto (GOLDBERG, 1968).

A visão de Sistemas Agroindustriais segue a tradição iniciada por Davis e Goldberg, porém inclui uma variável na análise do setor agroalimentar, a transaçã $0^{2}$. O Sistema Agroindustrial é visto como um nexo de contratos, com o objetivo de coordenar os agentes do sistema dando estímulos, controle, e agilidade no fluxo de informações do mercado para todos seus componentes (FARINA; AZEVEDO; SAES, 1997).

Sendo assim, os aspectos que tratam da coordenação dos SAG's ganham relevância, tanto teórica como prática, no sentido de equacionar os interesses dentro de um sistema rumo à sustentabilidade (CALEMAN et al., 2013). Os autores assinalam que o aporte teórico da Nova Economia Institucional (NEI), especificamente os estudos que tratam da importância e o papel das instituições como suporte das atividades de sistemas produtivos, bem como os que abordam a coordenação, podem colaborar no sentido de um melhor entendimento sobre a sustentabilidade em Sistemas Agroindustriais.

Duas correntes teóricas complementares foram importantes para o desenvolvimento e consolidação dessa arena de estudos e a formalização de modelos analíticos, denominadas de Ambiente Institucional e Instituições de Governança (AZEVEDO, 1997; WILLIAMSON, 1991). A primeira tem uma visão macroanalítica sobre os problemas econômicos, e a segunda, microanalítica, se concentra sobre a eficácia com que as formas genéricas de governança conseguem minimizar os custos de transaçã $0^{3}$ (WILLIAMSON, 1991).

Para North (1991), instituições são restrições (normas) construídas pelos seres humanos, que estruturam a interação social, econômica e política. Elas consistem em restrições informais (sanções, tabus, costumes, tradições e códigos de conduta) e regras formais (constituições, leis, e direitos de propriedade). North também inclui as estruturas responsáveis pela execução das regras formais

\footnotetext{
${ }^{2}$ As transações são as trocas entre os agentes econômicos, são os meios, sob força institucional, de adquirir e alienar o controle legal das mercadorias, do trabalho ou gestão que entrega produtos e serviços aos consumidores finais (COMMONS, 1931).

3"os custos ex-ante de preparar, negociar e salvaguardar um acordo bem como os custos ex-post dos ajustamentos e adaptações que resultam, quando a execução de um contrato é afetada por falhas, erros, omissões e alterações inesperadas. Em suma, são os custos de conduzir o sistema econômico" (WILLIAMSON, 1993).
} 
e das restrições informais, instituições seriam, portanto, as "regras do jogo", do jogo econômico, social, político ou do próprio jogo das instituições (NORTH, 1990).

Para analisar a influência das instituições no desenvolvimento econômico, esse arcabouço teórico vem trilhando dois caminhos: investigar as mudanças no ambiente institucional e seus efeitos sobre o desempenho econômico, e o outro, se concentra em teorizar sobre a criação das instituições (ZYLBERSZTAJN, 1995).

No entanto, para entender a restruturação econômica como respostas às mudanças institucionais é necessário entender a organização da produção como uma variável do próprio modelo (AZEVEDO, 1997). Esse é o foco da linha teórica Instituições de Governança, especificamente a Economia dos Custos de Transação (ECT), estudar as transações tomando as regras da sociedade como dadas (AZEVEDO, 1997; ZYLBERSZTAJN, 1995).

A ECT entende os custos de transação como indutores de modos de organização da produção (governança) dentro de um arcabouço analítico institucional (ZYLBERSZTAJN, 1995). "A ECT fornece os micro fundamentos ao estudo do ambiente institucional, ao mesmo tempo em que este último fornece a análise dos parâmetros macro institucionais aos quais as transações se referenciam" (AZEVEDO, 1997, p. 67).

As relações contratuais se caracterizam em termos das transações, ou seja, elas diferem umas das outras pelos seus atributos, tais como, especificidade dos ativos, frequência e incerteza, e estes explicariam a existência de diferentes estruturas de governança para reger as transações (AZEVEDO, 1997; WILLIAMSON, 1985).

A especificidade do ativo é dada quando um ativo não é reempregável em outra transação sem perda de valor, dado o pressuposto do oportunismo ${ }^{4}$ e a incompletude dos contratos, pois o agente é racionalmente limitado ${ }^{5}$ não prevê todas as contingências futuras que interferem na transação (AZEVEDO, 1997). "A especificidade é a característica de um ativo que expressa a magnitude de seu valor que é dependente da continuidade da transação a qual ele é específico" (AZEVEDO, 1997, p. 84). Essa característica está associada às formas de governança

${ }^{4}$ Oportunismo é a busca do autointeresse com avidez, toda via sem a crença de que todos os indivíduos ajam de maneira oportunista, ou seja, dada a hipótese de que algum agente tenha esse comportamento, as transações ficam expostas demandando monitoramento, consequentemente, gerando custos (ZYLBERSZTAJN, 1995).

${ }^{5} \mathrm{O}$ agente econômico é racionalmente limitado, pois não consegue prever todas as contingencias futuras de uma decisão econômica. Este pressuposto comportamental difere das escolas clássicas do pensamento econômico. adotadas uma vez que uma ação oportunista pode ocorrer, quebrando a relação de dependência para capturar as "quase rendas"” apropriáveis (ZYLBERSZTAJN, 1995).

O segundo atributo da transação, a frequência, está relacionado à escolha da estrutura de governança, na medida em que a mesma transação é repetida inúmeras vezes, diluindo os custos de adoção de um mecanismo complexo de contratos, além de abrir possibilidade de construção da reputação por parte dos agentes envolvidos na transação (AZEVEDO, 1997). A frequência com que ocorre uma transação determina a possibilidade de internalização de uma etapa produtiva sem perder a eficiência relacionada à escala (ZYLBERSZTAJN, 1995).

A última dimensão da transação é a incerteza. A incerteza está associada ao risco de comportamento oportunista o que implica em custos de transação, motivando a utilização de formas complexas de governança (ZYLBERSZTAJN, 1995). A incerteza amplia a complexidade da elaboração dos acordos diante da capacidade cognitiva limitada do agente, tornando os contratos incompletos sujeitos a ação oportunista, gerando custos de transação (ZYLBERSZTAJN, 1995; WILLIAMSON, 1985).

Williamson (1991) diferencia três formas de governança cada qual com um nível de mecanismos de coordenação, controle e capacidades de adaptação, dado um ambiente institucional (locus de parâmetros), a saber: mercado, hierarquia e formas híbridas, diferentes entre si pelo nível de eficiência relacionado às dimensões das transações. Encontra-se em Williamson $(2000 ; 2002)$ um modelo cognitivo de escolha das estruturas de governança alternativas ancorada na presença de ativos específicos (k) e salvaguardas ${ }^{7}$ (s). Conforme mostra a Figura 1.

Transações que não envolvem ativos específicos $(\mathrm{k}=0)$ serão efetuadas pela forma contratual do mercado (ponto A). Se a transação envolver ativos específicos $(\mathrm{k}>0)$ as partes gerarão incentivos e salvaguardas para proteção e continuidade da transação ou deixarão esses ativos desprotegidos tornando-os passíveis de captura de valor. O ponto $\mathrm{B}$ apresenta riscos contratuais que não foram considerados, dado a presença de ativos específicos, os quais estão expostos à captura pelos agentes, havendo instabilidade transacional (WILLIAMSON, 2002).

\footnotetext{
"Quase renda é definida como a diferença entre o retorno de um ativo empregado em uma transação específica e seu retorno em outro emprego alternativo. Esse montante é objeto de barganha entre as partes envolvidas na transação, na medida em que sua geração depende da continuidade do negócio" (Azevedo, 1997, p. 85).

${ }^{7}$ Mecanismos para proteção do ativo específico, dado o oportunismo e a racionalidade limitada do agente.
} 


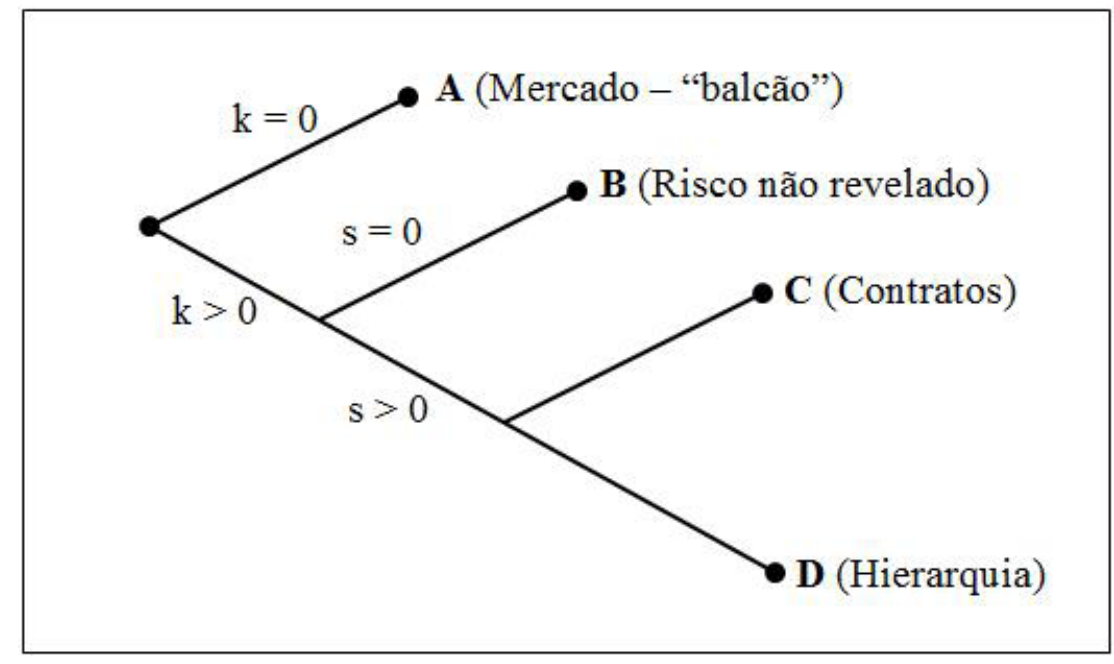

FIGURA 1 - Esquema contratual simplificado

Fonte: Williamson $(2000 ; 2002)$

Nos pontos C e D são fornecidas proteções contratuais. No ponto $\mathrm{C}$, contratos interfirmas são criados para a proteção dos ativos e continuidade da transação, e no caso do ponto D esses contratos ocorrem internamente a uma única organização (integração vertical) (WILLIAMSON, 2002).

\subsection{O Modelo Analítico para Sistemas Agroindustriais Sustentáveis}

O modelo para Sistemas Agroindustriais Sustentáveis, baseado nas premissas da Economia dos Custos de Transação, tem como unidade de análise as transações inerentes ao sistema. Os custos das transações ancorados em seus atributos, especificidade dos ativos, incerteza e frequência, serão a base para a análise da estrutura organizacional mais sustentável para reger essas transações.

Analogamente ao padrão proposto por Williamson (1991), SAG’s Sustentáveis apresentam duas pressuposições comportamentais, a racionalidade limitada e o oportunismo. Com o investimento em sustentabilidade surgem "quase rendas" sujeitas às ações oportunistas dos agentes demandando proteção para reger transações. Da mesma maneira, a racionalidade limitada impede que contratos protejam completamente os ativos sustentáveis, aumentando os custos de transação relacionados à "troca" da sustentabilidade.

Sugere-se que o agente, ao investir em sustentabilidade, está fazendo investimentos em ativos específicos dedicados a uma transação sustentável, os quais não seriam facilmente empregados findada a relação econômica.

Então, como será transacionado esse "produto" de alto investimento específico? Quais os incentivos e controles oferecidos aos agentes para continuidade desses investimentos em sustentabilidade? Qual a estrutura de governança adequada para sustentabilidade dos SAG's?

O modelo de análise traz formas alternativas de estruturas de governança sustentáveis para SAG's sustentáveis levando-se em consideração a presença de ativos específicos dedicados à sustentabilidade (condição necessária) e salvaguardas para proteção e continuidade da transação sustentável (condição necessária e suficiente). Em termos analíticos considera-se uma transação genérica $\left(T_{n}\right)$, demonstrada na Figura 2.

Esse esquema simples de contratação para transações sustentáveis indica que em SAG's sustentáveis ocorrem transações sustentáveis e estruturas de governança sustentáveis, dado investimento específico dedicado à sustentabilidade $\left(\mathrm{k}_{\mathrm{s}}\right)$ e salvaguardas (s).

Se a transação não envolver ativos específicos dedicados à sustentabilidade não haverá possibilidade da transação ser sustentável, resultado ancorado no pressuposto do modelo. A estrutura de governança adotada nesses casos é o mercado (ponto A). 


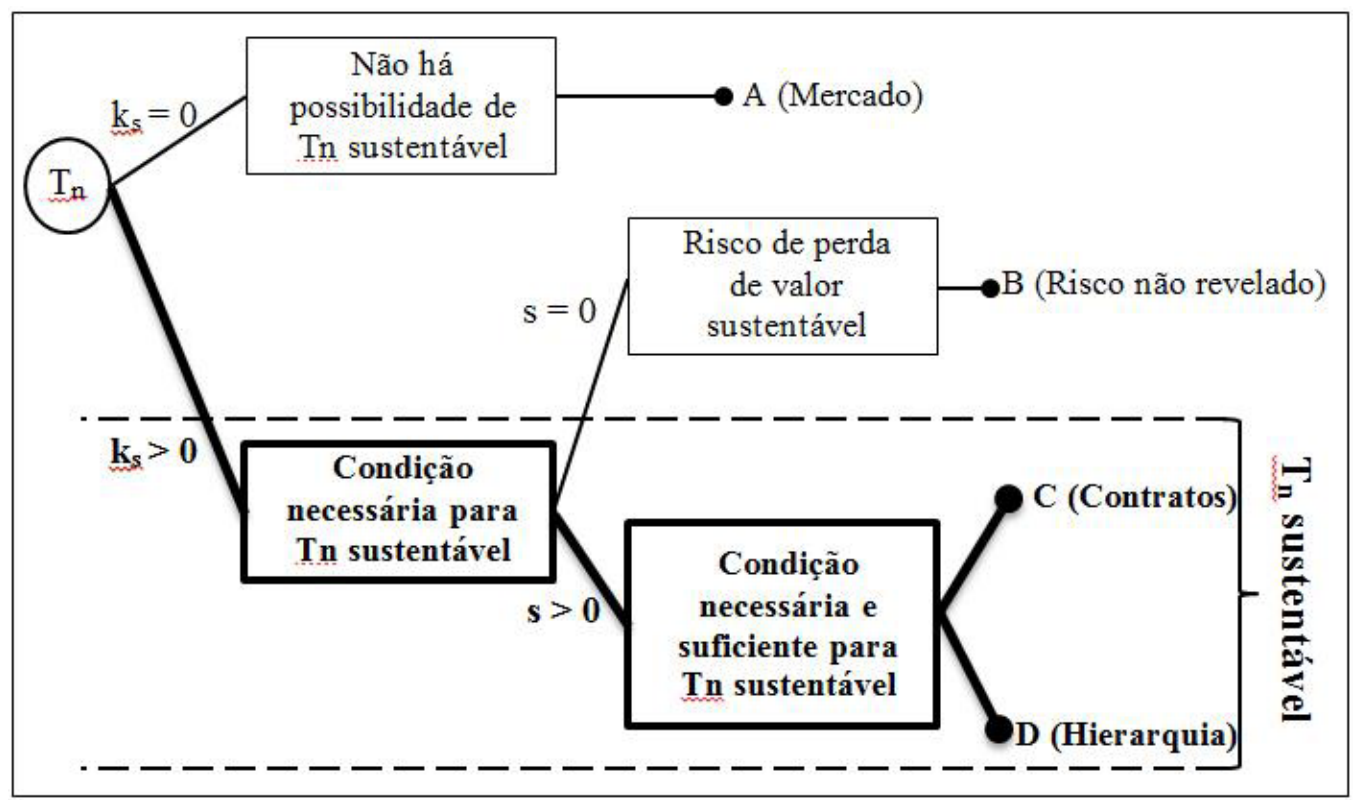

FIGURA 2 - Esquema simples de contratação para transações sustentáveis Fonte: elaborado pelo autor, baseado em Williamson (2000; 2002)

Dado o investimento em ativos específicos dedicado à sustentabilidade $\left(\mathrm{K}_{\mathrm{s}}>0\right)$ - condição necessária, mas não suficiente - três formas de governança são possíveis. A primeira trata-se da estrutura sem salvaguardas protetoras desses ativos (ponto B). Nessa situação, o investimento realizado estará vulnerável à captura de valor por outros agentes colocando em risco o ativo sustentável e a continuidade da transação, com possível perda de valor sustentável (risco não revelado).

A efetividade dos investimentos em ativos sustentáveis dependerá da existência de salvaguardas transacionais $(\mathrm{s}>0)$, condição suficiente para uma transação sustentável, dado investimento em ativos específicos dedicados à sustentabilidade (pontos $\mathrm{C}$ e D). Nesse caso, duas formas de governança surgirão, contratos e hierarquia, que serão escolhidas conforme os custos de transação envolvidos em cada forma organizacional.

Essa forma de abordagem apresenta três níveis de análise: as transações e o modo de governança entre os agentes econômicos (nível microanalítico), as transações do SAG como um todo (T1, T2, T3 e T4) nível mesoanalítico - e a capacidade das instituições e organizações afetarem a coordenação nos SAG's sustentáveis - nível macroanalítico (Figura 3).

O último nível de análise a ser considerado é o macroanalítico. As instituições são capazes de afetar a capacidade de coordenação de um Sistema Agroindustrial rumo à sustentabilidade. É o que ocorre com a criação de uma lei ambiental ou quando ocorrem pressões de organizações não governamentais sobre empresas que geram algum dano socioambiental, ou que não cumprem metas acordadas dentro de um sistema produtivo.

Em suma, no modelo para análise de SAG's Sustentáveis estão presentes ativos específicos dedicados à sustentabilidade, esses ativos demandam estrutura de governança sustentável (mercado, híbrida ou hierárquica) que reduza os custos de "transacionar" a sustentabilidade. Incerteza, frequência, o ambiente institucional e organizacional são variáveis consideradas parâmetros de deslocamento, ou seja, dado um nível de especificidade dos ativos dedicados à sustentabilidade, a presença ou não dessas variáveis interfere na escolha da estrutura de governança adequada.

Assim, é preciso um mecanismo que reduza o custo de "troca" da sustentabilidade dentro do sistema, considerada a necessidade de investimento em um ativo específico, dado um ambiente organizacional e institucional, onde a racionalidade é limitada e o oportunismo são pressupostos comportamentais. Essa indução é dada a partir da condição necessária (investimentos específicos dedicados à sustentabilidade $\mathrm{Ks}>0$ ) e da condição necessária e suficiente (salvaguardas, $\mathrm{S}>0$ ) para proteção e continuidade desses ativos. 


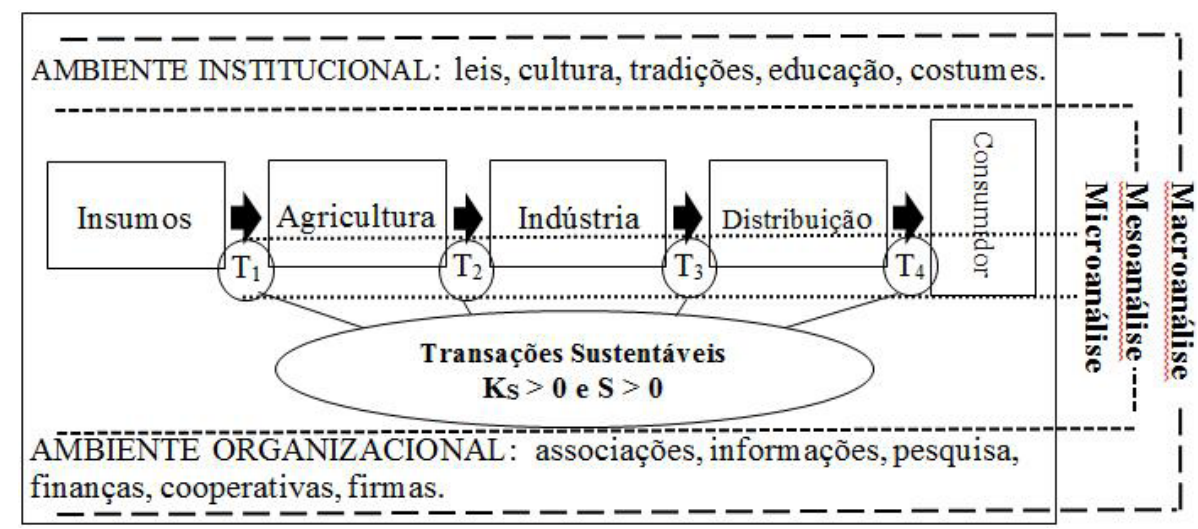

FIGURA 3 - Sistemas Agroindustriais Sustentáveis e seus níveis de análise Fonte: Elaborado pelo autor

\section{RESULTADOS E DISCUSSÃO}

\subsection{Caso 1 - Associação Sul-mato-grossense de Produtores de Novilho Precoce - ASPNP}

A origem da ASPNP está relacionada à criação do Programa Novilho Precoce em MS pelo Decreto Estadual 6.344, de 30 de janeiro de 1992, que tinha como objetivo estimular a criação e desenvolvimento de animais precoce para o abate, aumentando o rendimento econômico da atividade (ALMEIDA et al., 1996). A ideia era premiar financeiramente os produtores pela qualidade do novilho abatido com a redução do Imposto Sobre Circulação de Mercadorias e Serviços (ICMS) traduzido como ganho do produtor, após o expurgo de quaisquer benefícios concedidos genericamente ao setor dos frigoríficos.

Nesse contexto, em 1998 foi fundada por um grupo de pecuaristas a ASPNP. O objetivo da associação era produzir animais precoces com qualidade que atendessem às demandas do mercado, aliado à regularidade do produto visando à obtenção de parcerias comerciais para maior lucratividade dos produtores. Tais parcerias visam à negociação com preço prêmio para o animal melhor qualificado. Segundo o diretor técnico da ASPNP, Antônio João de Almeida, "A ASPNP está apoiada na melhor gestão das unidades produtivas dos associados, que garantem o tripé da associação: qualidade da carne, volume produzido e regularidade de oferta. Essas características garantem o sucesso das parcerias com frigorificos e redes distribuidoras".

Em 2013, após 15 anos de existência e 700 mil animais abatidos, a ASPNP contou com mais de 300 associados, com rebanho estimado em 800 mil cabeças, abatendo mais de 140 mil animais por ano com qualidade, regularidade e padronização, alcançando mais de 6 milhões em bonificações no mesmo ano. A meta atual do programa é produzir 400 mil novilhos precoces por ano, ter três mil produtores cadastrados e adequar indústrias cadastradas às normas ambientais e sociais.

Mas, por que a ASPNP está presente em um estudo sobre sustentabilidade da carne de Mato Grosso do Sul? Em primeiro lugar, o sistema de qualidade implantado pela associação possibilita analogias com algumas questões sobre transação de ativos específicos e sua coordenação. Além disso, a natureza de seu programa de qualidade contempla algumas questões ambientais e sociais, como, por exemplo: bem estar animal, adequação às leis ambientais e trabalhistas, práticas de conservação do solo, gestão ambiental, sistemas de integração lavoura-pecuária, entre outros.

A associação conta com a adoção do Programa Boas Práticas Agropecuárias (BPA) da Embrapa Bovino de Corte. Para a ASPNP o BPA é uma ferramenta de gestão que melhora a produtividade dentro da fazenda, mas que futuramente pode ser remunerada com preços prêmios por práticas sustentáveis ${ }^{8}$, ou seja, "a associação toma frente em algumas ações em sustentabilidade através do $B P A$ acreditando que em algum momento o mercado irá recompensá-los, pois a questão ambiental e social é um caminho sem volta".

${ }^{8}$ Entrevista da Embrapa Gado de Corte com Alexandre Scaff Raffi, presidente da ASPNP.

${ }^{9}$ Entrevista pessoal com Antônio João de Almeida, diretor técnico da ASPNP e produtor associado. 
A adesão pelos produtores associados à ASPNP ao programa BPA é voluntária. Em 2013, 14 produtores receberam atestado de conformidade do BPA, e há 50 em processo de implantação. "Contudo, ainda é dificil convencer o associado aderir ao BPA, pois exige investimentos sem ganhos explícitos na venda da carne, afinal, por que o produtor investiria em sustentabilidade sendo que será pago o mesmo preço pela carne dele?" 10 .

O pressuposto do modelo de análise de SAG's sustentáveis é a existência de investimento em ativos específicos dedicados à sustentabilidade. O que é identificado nos discursos citados anteriormente. "Exemplos desses investimentos são: para o bem- estar animal o produtor precisa adaptar as instalações rurais como currais, rampas de embarque, dar treinamento para os funcionários para o manejo adequado do gado com educação ambiental, proporcionar moradia de qualidade aos funcionários, entre outros", declara o diretor de sustentabilidade Ezequiel Rodrigues do Valle.

Um ativo específico dedicado à sustentabilidade perde seu valor com a não continuidade da transação. Esses investimentos são condição necessária, porém não suficiente para termos uma transação sustentável e, consequentemente, um sistema sustentável. Nesse sentido, dado o investimento em um ativo específico dedicado à sustentabilidade, qual a forma de coordenação adotada pela ASPNP para essa transação?

${ }^{10}$ Entrevista pessoal com Ezequiel Rodrigues do Valle, diretor de Sustentabilidade da ASPNP.
Em se tratando do tema da qualidade, a ASPNP, desde a sua criação, elabora parcerias de comercialização. Contratos garantem preço prêmio quando da qualidade do lote abatido. Esses relacionamentos caracterizam a estrutura de governança adotada na transação entre os produtores (representados pela associação) e os elos adiante do sistema.

Contudo, esse modo de coordenação não se dá em se tratando das questões e práticas relativas ao tema da sustentabilidade. O produtor que adere o programa BPA não garante nenhuma remuneração diferenciada, ou seja, seu novilho será transacionado da mesma maneira que um novilho cujo fazendeiro não é atestado pelo programa. Sendo assim, no que tange a sustentabilidade, ainda há o risco de captura de valor por uma ação oportunista dentro do sistema, conforme mostra a Figura 4.

Tendo em vista essas análises, considera-se que a ASPNP deu o primeiro passo rumo à sustentabilidade de sua transação. Entretanto, se essas ações não forem abrigadas, por meio de uma estrutura de governança mais eficiente, dado o surgimento de custos de transação relativos aos ativos específicos dedicados à sustentabilidade, a continuidade e a aderência das práticas podem correr riscos.

As instituições, consideradas as "regras do jogo", são capazes de influenciar a coordenação das transações em um sistema agroindustrial, assim como as organizações. E a ASPNP é um exemplo oportuno para a observação dessas influências e para analogias considerando sistemas que busquem a sustentabilidade.

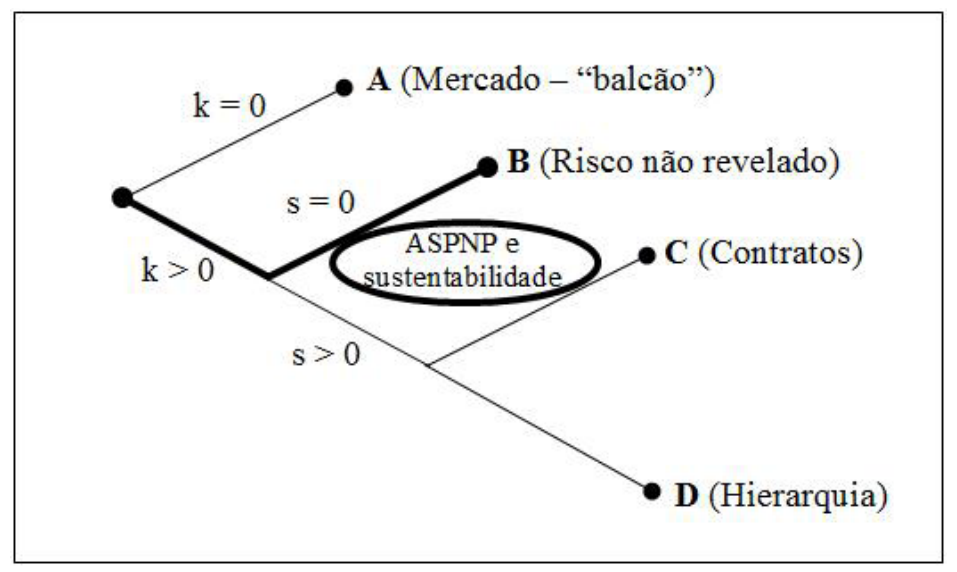

FIGURA 4 - Esquema contratual para sustentabilidade ASPNP

Fonte: elaborado pelo autor

Organizações Rurais \& Agroindustriais, Lavras, v. 18, n. 4, p. 315-331, 2016 
O mercado de carne de qualidade e procedência, bem como a própria associação, sofreu influência direta de uma instituição, o Decreto Estadual 6.344, de 30 de janeiro de 1992, que criou o Programa Novilho Precoce no MS. Antônio João de Almeida, diretor técnico da ASPNP, que participou de toda a criação do programa e da associação, declara que "graças ao programa decretado pelo governo do estado, os produtores enxergaram que era necessário e possivel investir em qualidade e produtividade da fazenda, e a associação surgiu também por conta desse programa, que permitiu avistarmos possibilidades de parcerias para que recebêssemos algo a mais pela qualidade da carne, $e$ isso se concretizou através de contratos com os frigoríficos e redes de distribuição".

O mesmo diretor observa que a cultura, outra instituição muito forte, foi ponto chave para o sucesso da ASPNP e do programa: "foi necessária uma mudança cultural muito grande. Antes os produtores acreditavam que o frigorífico era nosso eterno inimigo e que não era possível negociarmos com eles. Mas houve uma mudança cultural significante, não tratamos a indústria como antes, ela é nossa parceira nos negócios".

Essas afirmações deixam claras as influencias que as instituições exercem sobre a coordenação de uma transação e de um sistema produtivo rumo à sustentabilidade. "Se algo acontecesse nesse sentido relacionado ao programa BPA, como por exemplo, incentivos fiscais para os produtores que aderissem ao programa, certamente estaríamos com maior número de adeptos e negociando com os frigorificos e distribuidores melhores preços para esses produtores do BPA", são palavras do diretor de sustentabilidade da ASPNP, Ezequiel Rodrigues do Valle.

As organizações também afetam a coordenação das transações rumo a um SAG sustentável. A ASPNP é uma organização que ofereceu aos produtores poder de barganha para a concretização dessa estrutura de governança remuneradora da qualidade da carne. "Se não fosse a Novilho Precoce não teríamos condições, individualmente, de negociar com o frigorífico. Eu imagino que o programa não continuaria, e os produtores acabariam desistindo da ideia", é o que diz Antônio João de Almeida.

Diante do exporto, uma análise geral sobre a ASPNP mostra que as ações em sustentabilidade incorporadas na associação, por meio do BPA estabelecem investimentos em ativos específicos dedicados à sustentabilidade. A transação desse ativo deve ser feita da maneira mais eficiente possível, pois há o risco da não continuidade dessas ações findadas a relação econômica. A analogia feita no caso é a coordenação adotada pela ASPNP para a produção de carne de qualidade (novilho precoce). A estrutura de governança dá pistas para a reprodução em sistemas sustentáveis.

Contudo, a ASPNP não adota uma estrutura de coordenação adequada para a sustentabilidade da transação produtor-indústria $\left(\mathrm{T}_{2}\right)$. Apesar de existir investimentos em ativos específicos para a sustentabilidade, não há salvaguardas na transação desse ativo, incorrendo em riscos de perda de valor sustentável e não continuidade da transação. O nó "B" representa essa situação de instabilidade (ver Figura 4).

O caso mostrou a capacidade das instituições, como, por exemplo, o Decreto Estadual 6.344, de 30 de janeiro de 1992, afetarem a coordenação de um sistema produtivo de qualidade, bem como a influência das organizações (ASPNP e BPA). Não obstante, a ASPNP apesar de não adotar a estrutura adequada para a sustentabilidade, conta com contratos para o sistema de qualidade, fator que pode levar ao efetivo estabelecimento das questões sustentáveis, principalmente com o sucesso da adoção do programa BPA.

\subsection{Caso 2 - Boas Práticas Agropecuárias (BPA) - Bovinos de Corte Embrapa}

O programa Boas Práticas Agropecuárias Bovinos de Corte (BPA) foi lançado oficialmente, em 2005, no Estado de Mato Grosso do Sul, uma iniciativa da Embrapa Gado de Corte e da Câmara Setorial da Bovinocultura e Bubalinocultura de MS instituído por meio da portaria Interministerial MAPA/MA/MET N ${ }^{\circ} 36$, de 25 de Janeiro de 2011 (BRASIL, 2011).

Tem como finalidade adequar as propriedades rurais interessadas ao processo de melhorias do sistema de produção, a fim de assegurar qualidade, reduzir custos e garantir o fornecimento de alimentos seguros provenientes de sistemas sustentáveis. O BPA bovinos de corte é um aparelho de parcerias entre os produtores, entidades de representações do setor e órgãos do governo, concretizado em um manual de procedimentos de boas práticas que orienta o produtor rural na utilização adequada das tecnologias sustentáveis em consonância com os requisitos econômicos, sociais e ambientais da produção.

O manual expõe ações dentro de 11 eixos temáticos traduzidos em uma lista de verificação para a adequação das propriedades. A adesão ao programa é livre e voluntária. O produtor interessado procura as entidades responsáveis pela implantação do programa, que, no Mato Grosso do Sul, está a cargo do Serviço Nacional de Aprendizagem Rural (SENAR). 
Em 2013, foram 48 propriedades inscritas, sendo 10 fazendas independentes e 38 associadas à ASPNP (caso 1). Dentre elas, 13 propriedades vinculadas à ASPNP e apenas 1 propriedade independente foram atestadas pelo BPA. "Essas fazendas atestadas, além de fazer o uso correto das inúmeras tecnologias disponiveis, contam com processos produtivos e suporte de sistemas de gestão que contemplam os aspectos social, ambiental e econômico, de modo a assegurar a rentabilidade e a competitividade dos empreendimentos rurais com sustentabilidade", relatou Ezequiel Rodrigues do Valle, coordenador nacional do programa.

Contudo, o BPA não conta com uma visão sistêmica para a sustentabilidade. "O programa é direcionado exclusivamente para dentro da porteira, nós estamos preocupados excepcionalmente com a produtividade e a sustentabilidade das propriedades rurais". Há ainda resistência em relação à adoção do programa relacionada à necessidade de investimentos para a adequação do produtor, como, por exemplo, os custos que estão diretamente relacionados à questão da sustentabilidade. O coordenador do BPA conta que alguns produtores pedem para retirar a questão ambiental da lista de verificação.

Dos 14 produtores atestados, em 2013, a maioria precisou investir na propriedade. A maioria dos investimentos foi em relação às questões ambiental e social, apesar de contarem com sistemas de gestão avançados. A análise da entrevista, bem como dos documentos do programa, como o Manual de Orientações e a Lista de Verificação, deixa claro que o BPA não prevê ações de coordenação da transação entre os produtores e os elos adiante do sistema, dado o investimento específico em sustentabilidade. Nas palavras do idealizador do programa: "Não é papel da Embrapa trabalhar com alianças fora da porteira, nós nos preocupamos dentro da porteira".

Assim como o caso da ASPNP, o BPA também não adota uma estrutura eficiente para transação de um ativo específico dedicado à sustentabilidade. Não há nada que garanta ao produtor a apropriação do valor investido para atender às questões ambientais e sociais propostas pelo programa, conforme mostra a Figura 5. O nó "B" da Figura 5 representa uma situação de instabilidade, onde o ativo está sujeito à captura de valor por qualquer agente que agir de maneira oportunista dentro do sistema. Mas qual a diferença desse caso para o primeiro?

No caso da ASPNP, apesar de não contar com formas de proteção do ativo sustentável, a estrutura de governança adota pela associação é menos instável que a do BPA, pois há contratos que remuneram a qualidade da carne dos associados que foram atestados pelo BPA na ASPNP. Para um produtor atestado pelo BPA que não seja um associado da Novilho Precoce os riscos de perda de valor são maiores, assim como os incentivos para continuar com o programa são menores, ou seja, a situação envolve maior instabilidade, podendo se aproximar da situação de mercado, onde entende-se que os ativos específicos sustentáveis são iguais a zero (nó “A”).

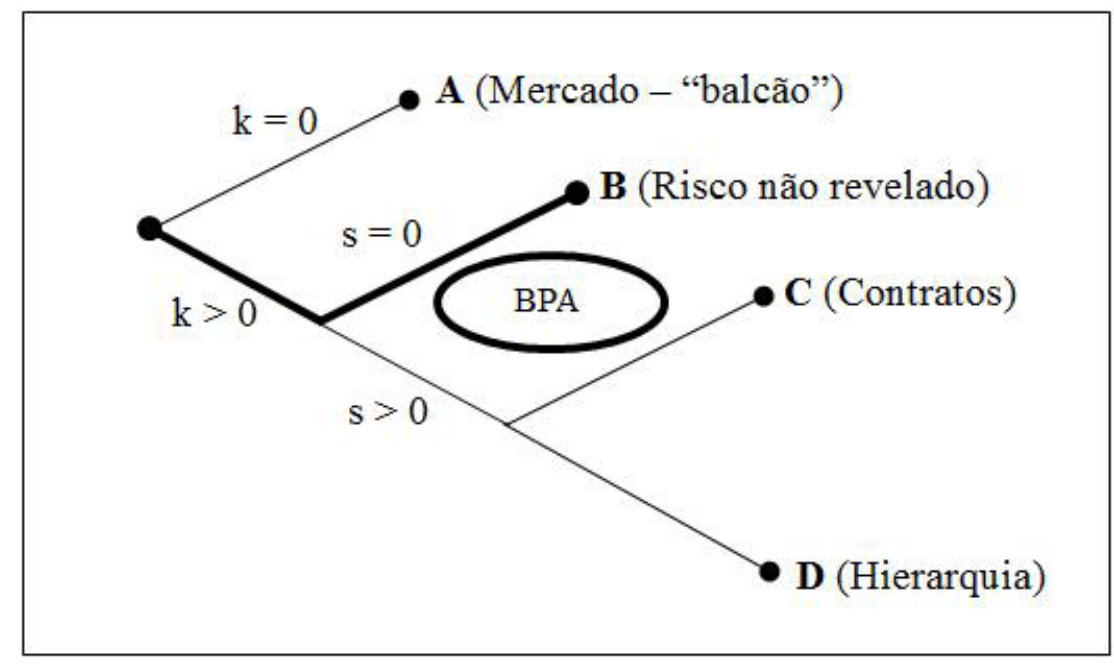

FIGURA 5 - Esquema contratual para sustentabilidade BPA

Fonte: elaborado pelo autor

Organizações Rurais \& Agroindustriais, Lavras, v. 18, n. 4, p. 315-331, 2016 
Talvez isso possa explicar por que dentre as 48 propriedades inscritas no Mato Grosso do Sul para o BPA em 2013, apenas 10 eram independentes e 38 membros da Novilho Precoce. Dessas dez propriedades apenas uma conseguiu o atestado (10\%), e das 38 associadas à ASPNP, 13 foram contempladas (35\%).

Essa noção está presente no discurso do coordenador nacional do programa: "Sabe-se que é preciso engenhar formas para que o programa ganhe maior aderência dos produtores em geral. Neste sentido, a Embrapa juntamente com o comitê gestor do programa e a Secretaria de Assuntos Estratégicos da Presidência da Republica (SAE) estudam formas para incentivar as Boas Práticas Agropecuárias na pecuária de corte através das organizações e instituições".

Em se tratando do papel das instituições e organizações, pode-se observar a importância da portaria Interministerial $\mathrm{n}^{\circ} 36$ de 26 de janeiro de 2011, que desenvolveu e promoveu o BPA em âmbito nacional. Dessa forma, o programa foi instituído, tornando possível a viabilidade do projeto, bem como provendo custeio, por meio dos ministérios participantes e demais entidades para a realização de ações realizadas no BPA. Além disso, há estudos para possíveis parcerias com organizações financeiras para a implantação de linhas de crédito diferenciadas para os produtores que queiram aderir ao programa. Um exemplo é a linha de crédito "Intensifica Pecuária". Ainda em estudo, essa linha de crédito poderá adotar a Lista de Verificação do BPA para distribuir crédito a juros menores que os disponíveis no mercado aos produtores que queiram investir em sustentabilidade.

O mesmo plano examina a possibilidade de gerar incentivos fiscais para a produção sustentável de carne bovina. Segundo Ezequiel Rodrigues do Valle, "surgiu um novo interesse por parte da SAE em relação ao BPA. Estamos estudando a possibilidade de desoneração da indústria frigorifica para que ela pague mais pela carne sustentável". Essas estratégias influenciariam o modo de governança entre os agentes desse sistema, diminuindo os custos de transação envolvidos na troca do ativo específico dedicado à sustentabilidade.

\subsection{Caso 3 - Associação Brasileira de Pecuária Orgânica (ABPO)}

AABPO nasceu, em 2001, pelas mãos de criadores de gado da planície pantaneira que identificaram na pecuária orgânica certificada uma atividade produtiva próspera do ponto de vista econômico, ambiental e social ${ }^{11}$.

${ }^{11}$ Entrevista pessoal com Leonardo Leite de Barros, presidente da ABPO.
O objetivo da associação é agregar valor à carne bovina produzida no Pantanal, por meio da melhoria da rentabilidade do negócio pecuário, garantindo a manutenção do meio ambiente, da sua biodiversidade, da preservação e sustentação da cultura do "Homem Pantaneiro" e de sua família, disponibilizando carne segura de qualidade, que tenha as questões sociais e ambientais resolvidas.

O sucesso da ABPO está diretamente relacionado às parcerias firmadas desde o inicio do projeto. Segundo Leonardo de Leite Barros, a principal missão da associação é agregar valor aos associados, por meio da gestão de negócios, que são possíveis através das alianças formadas com atores chave do sistema.

Uma aliança fundamental foi com a WWF-Brasil. A ONG, pelo qual o programa Pantanal foi responsável por financiar as 10 primeiras certificações da ABPO, além de intermediar diálogos entre a associação e outros agentes, principalmente com a indústria ${ }^{12}$. Além da WWF-Brasil e outra ONG's, são parceiros da ABPO, fabricantes de insumos (Real-H), indústrias de processamento de carne bovina (JBS e Navicarnes), instituições de pesquisa (Embrapa, UFMS, ESALQ-USP), empresas distribuidores de carne (Korin, Verde Mar).

Entre os anos de 2004 e 2005, foram 10 propriedades certificadas. Em 2013, foram 110 mil hectares com certificação, envolvendo 20 fazendas localizadas nas sub-regiões da "Nhecolândia" e "Nabileque" no Pantanal Sul-mato-grossense, com um rebanho estimado em 55 mil cabeças de gado (ABPO, 2013).

No que tange à esfera social, a ABPO atende plenamente à legislação trabalhista brasileira, sendo todos os funcionários registrados com acesso à moradia digna, alimentação, saúde e educação. Os trabalhos escravo e infantil são proibidos e combatidos. As metas da associação são manter o homem pantaneiro e a sua família no pantanal, promover a cultura pantaneira, garantir o acesso das populações isoladas à educação, disponibilizar cursos e capacitações para valorização da mão de obra e melhorar o acesso ao atendimento médico e odontológico, proporcionando qualidade de vida aos pantaneiros.

Em relação à questão ambiental, a $\mathrm{ABPO}$ cumpre integralmente às legislações ambientais brasileiras, bem como atende às exigências do código florestal, com áreas de reserva legal e de proteção permanente. É vetado o uso de agrotóxicos nas propriedades, as quais têm a

${ }^{12}$ Entrevista pessoal com Ivens Teixeira Domingos, técnico do Programa Pantanal da WWF-Brasil. 
obrigação de conservar os recursos hídricos e o solo. Os objetivos a serem alcançados contemplam a continuidade do modelo de pecuária extensiva, fator determinante para a preservação do bioma pantaneiro, a busca pela melhoria continua dos processos e o desenvolvimento de projetos para a conservação do meio ambiente.

Essa noção de sustentabilidade é materializada principalmente pela adoção de certificação para a produção de carne orgânica. O Instituto Biodinâmico (IBD) é a entidade certificadora responsável pela auditoria e credenciamento das propriedades. O IBD conta com o credenciamento INFOAM para a venda de produtos orgânicos no mercado internacional, dentre suas exigências estão adequação da estrutura geral da propriedade enquanto organismo agrícola, adubação orgânica para produção animal, controle natural de pragas e doenças, reguladores de crescimento e de contaminação e adequação das mudas e sementes, sendo proibido uso de Organismos Geneticamente Modificados. A rastreabilidade é item fundamental no processo de produção de carne orgânica, já que a adequação dos procedimentos só é garantida, por meio da identificação e acompanhamento integral da produção animal.

O processo de certificação envolve investimentos para a adequação das pastagens, para a preservação do solo e dos recursos hídricos, recuperação de áreas degradadas, reflorestamento, investimento no que tange a rastreabilidade total dos animais, o que envolve treinamento e capacitação dos funcionários. Esse processo é lento e custoso, pois existe um tempo de conversão da produção convencional para produção orgânica.

Uma característica interessante desse processo é a exigência de que todo o sistema esteja adequado, ou seja, os produtores obrigatoriamente compram insumos de fábricas certificadas e vendem para indústrias e distribuidores também adequadas à produção orgânica.

A maneira eficiente encontrada para proteger esses investimentos tem sido parcerias comerciais, feitas, por meio de contratos de fornecimento com indústrias e empresas distribuidoras. No ano de 2013, foi firmado acordo entre a ABPO e a Korin, empresa que produz e comercializa produtos de origem orgânica e sustentável. O mesmo prevê a venda de animais provenientes da ABPO, a qual será comercializada como carne sustentável do pantanal. Apesar de não pagar preço prêmio na arroba do boi, acessa mercados diferenciados. O abate é feito pelo frigorífico Navicarnes, que entrega a carne para Korin, a qual fica responsável pela distribuição.
$\mathrm{O}$ segundo contrato, entre a $\mathrm{ABPO}$ e a rede Verde Mar de Supermercados do estado de Minas Gerais, também ocorre na mesma estrutura da anterior. A ABPO entrega os animais para abate ao Navicarnes, que, por sua vez, entrega para os Supermercados Verde Mar, os quais vendem a carne com a marca "Bullight". Esse contrato prevê o pagamento da arroba mais prêmio de $3 \%$, desde que o boi tenha até no máximo 4 dentes de leite.

O terceiro contrato, e mais duradouro, é com o frigorífico JBS. Essa relação está diretamente ligada à história da $\mathrm{ABPO}$, pois foi uma das parcerias que viabilizaram o negócio. Em 2005, a JBS lançou uma linha de carne orgânica, a "Organic Beef Friboi", ao mesmo tempo foi firmado um contrato de fornecimento com a ABPO. O acordo previa o abate de 280 animais por mês, sendo pago o preço da arroba mais $10 \%$ de premio se o animal atingisse acabamento de $2 \mathrm{~mm}$ de gordura, idade de 2 a 4 dentes de leite, acima de 10 arrobas.

"Se não fossem por esses contratos de fornecimento, principalmente os de preço premio, certamente a associação encerraria suas atividades", diz o presidente da associação, Leonardo Leite de Barros. O mesmo relata que tem "insistido muito na questão da viabilização do negócio sustentável, e isso só é possível com a garantia da venda e do volume vendido através de contratos com a indústria e distribuição, pois a cobrança maior é em cima do produtor, mas precisamos de garantias para que o negócio dê certo".

Sendo assim, os dados mostram que a ABPO e , respectivamente, seus associados, investem em ativos específicos dedicados à sustentabilidade, ao mesmo tempo, protegem esses investimentos, por meio de contratos de fornecimento (condição suficiente), sinalizando para operacionalização da sustentabilidade tendo em vista o modelo de SAG’s sustentáveis proposto, conforme Figura 6.

Como visto no decorrer do caso, uma organização fundamental para a ABPO foi a WWF-Brasil. "O grande papel de uma $O N G$, além de garantir que os processos são sustentáveis na produção, é tentar fortalecer essas associações na negociação com os outros elos da cadeia", diz Ivens Teixeira Domingos.

Além da WWF, outras organizações foram fundamentais para a viabilização desses contratos, como é o caso da Associação Brasileira de Animais Orgânicos (ASPRANOR). Em 2005, a ABPO ainda não contava com volume suficiente para a realização da parceria com o JBS. Inicialmente a $\mathrm{ABPO}$ vendia carne orgânica, por meio da ASPRANOR. Logo que conseguiu volume de produção suficiente o próprio contrato foi firmado. 


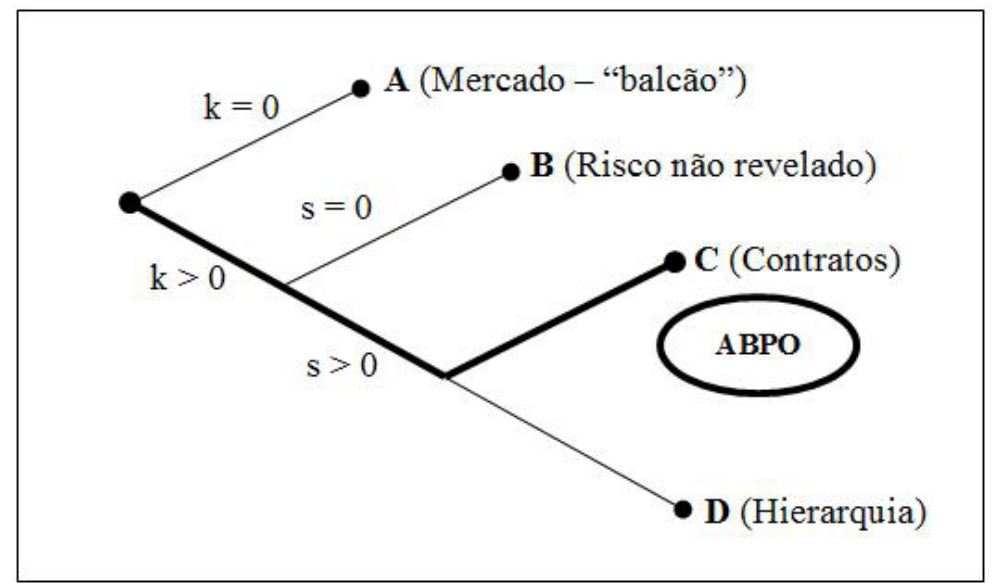

FIGURA 6 - Esquema contratual para sustentabilidade ABPO

Fonte: elaborado pelo autor

Quanto ao ambiente institucional são identificáveis algumas legislações determinantes para a produção e comercialização de produtos orgânicos como, por exemplo, a Lei 10.831, de 23 de dezembro de 2003 que aprova a cultura e comercialização dos produtos orgânicos no Brasil, com regulamentação em 27 de dezembro de 2007 e publicação do Decreto $\mathrm{N}^{\mathrm{o}} 6.323$.

Segundo Leonardo de Leite Barros, "apesar de não esperar muito do governo, um incentivo fiscal seria um grande passo para expansão da carne orgânica no MS, pois facilitaria e muito a adesão de proprietários e também na comercialização da carne orgânica", o que deixa claro o poder de influencia de uma instituição sobre a coordenação de um sistema rumo à sustentabilidade.

De maneira geral, há menor nível de instabilidade das transações realizadas pela $\mathrm{ABPO}$ do que pelos produtores dos casos 1 e 2, fazendo com que a sustentabilidade seja operacionalizada de maneira eficiente.

\subsection{Análise Cruzada dos Casos}

No Quadro 1, apresenta-se uma síntese dos casos estudados. Observa-se que o caso ABPO é o que mais se aproxima de um sistemas agroindustrial sustentável, visto que há investimentos em ativos específicos dedicados à sustentabilidade e mecanismos de governança (contratos) desenvolvidos para coordenar e proteger, por meio de salvaguardas os produtores da possibilidade de comportamento oportunista e da captura das quase rendas criadas. Ainda, o pagamento de prêmios (bônus) aos produtores que fornecem o animal orgânico promove incentivos para a continuidade da transação.
O caso ASPNP que envolve produtores de novilhos precoces que adotam as boas práticas de produção animal (Embrapa Gado de Corte) ilustrariam um sistema agroindustrial sustentável, porém, cujas práticas voltadas à sustentabilidade não são incentivas por meio de bonificação e cuja quase renda criada é ainda sujeita à captura por parte das indústria de abate e processamento. Por fim, o caso BPA Embrapa Gado de Corte, apesar de estar intrinsicamente relacionado ao tema da sustentabilidade ilustra um sistema agroindustrial instável, uma vez que não há mecanismos de proteção e incentivo aos investimentos específicos dedicados à sustentabilidade. Ainda, no caso BPA constata-se a ausência de mecanismos de coordenação horizontal que contribuem na melhoria do poder de barganha em processos de negociação com a indústria de abate e processamento.

Na Figura 7, detalham-se os três casos estudados, destacando as a relação entre investimento em ativo específico dedicado à sustentabilidade, mecanismos de governança, salvaguardas e ambiente institucional. Essa análise geral pretende ilustrar como o modelo analítico permite a identificação de pressupostos e a proposição de hipóteses, passíveis de validação em pesquisas futuras.

Com base na Figura 7, é possível propor que para o estudo de sistemas agroindustriais sustentáveis, a unidade de análise é a transação e variável chave é a especificidade dos ativos dedicados à sustentabilidade, sendo as instituições consideradas parâmetros de deslocamento, capazes de influenciar a capacidade de coordenação das transações sustentáveis. 
QUADRO 1 - Categorias de análise e os casos investigados

\begin{tabular}{|c|c|c|c|}
\hline Categorias de análise & ASPNP & BPA - Embrapa & ABPO \\
\hline $\begin{array}{l}\text { Ativo específico dedicado à } \\
\text { sustentabilidade }\end{array}$ & $\begin{array}{c}\text { Investimentos em bem } \\
\text { estar animal (adaptação de } \\
\text { instalações rurais, treinamento } \\
\text { para o manejo adequado do } \\
\text { gado com educação ambiental, } \\
\text { moradia de qualidade aos } \\
\text { funcionários) }\end{array}$ & $\begin{array}{l}\text { Investimento em sistemas de } \\
\text { gestão que contemplam os } \\
\text { aspectos social, ambiental } \\
\text { e econômico da produção } \\
\text { pecuária. }\end{array}$ & $\begin{array}{c}\text { Investimento em } \\
\text { rastreabilidade e certificação } \\
\text { para a produção de animais } \\
\text { orgânicos }\end{array}$ \\
\hline $\begin{array}{c}\text { Mecanismos de coordenação } \\
\text { vertical }\end{array}$ & $\begin{array}{c}\text { Contratos de comercialização } \\
\text { de animal precoce }\end{array}$ & Não há & $\begin{array}{c}\text { Contratos de comercialização } \\
\text { de animais orgânicos }\end{array}$ \\
\hline $\begin{array}{c}\text { Mecanismos de coordenação } \\
\text { horizontal }\end{array}$ & Associação de produtores & Não há & Associação de produtores \\
\hline Incentivo & Bônus pago ao animal precoce & Não há & $\begin{array}{l}\text { Bônus pago ao animal } \\
\text { orgânico }\end{array}$ \\
\hline Ambiente institucional & $\begin{array}{c}\text { Decreto Estadual } 6344 \\
\text { (30/01/1992) - criação do } \\
\text { Programa de Novilho Precoce } \\
\text { / MS }\end{array}$ & $\begin{array}{l}\text { Portaria Interministerial } \\
\text { MAPA/MA/MET n }{ }^{\circ} 36 \\
\qquad(25 / 01 / 2011)\end{array}$ & $\begin{array}{c}\text { Lei } 10.831(23 / 12 / 2003) \text { - } \\
\text { comercialização dos produtos } \\
\text { orgânicos no Brasil; Decreto } \\
\mathrm{N}^{\circ} 6.323 \text { ( regulamentado em } \\
27 / 12 / 2007) .\end{array}$ \\
\hline
\end{tabular}

Todos os casos mostraram evidências de que sustentabilidade exige investimentos traduzidos nas ações ambientais, sociais e econômicas, paradigma presente no SAG da carne bovina de Mato Grosso do Sul. Porém, também mostraram a necessidade de entender como a sustentabilidade pode ser operacionalizada, em se tratando da transação desses investimentos em ativos específicos dedicados à sustentabilidade. Assim, temse como pressuposto: SAG's sustentáveis envolvem transações dotadas de ativos específicos dedicados à sustentabilidade $\left(\mathbf{k}_{\mathrm{s}}>\mathbf{0}\right)$.

Apesar da transação entre produtores da ASPNP e dos atestados pelo BPA com o frigorífico apresentar ativos específicos dedicados à sustentabilidade não há salvaguardas que protejam esses ativos, que estão passíveis de captura e perda de valor, não sendo a forma mais adequada de governança para a operacionalização da sustentabilidade no SAG. Já o caso da ABPO mostrou que os produtores guardam esses ativos por meio de contratos de fornecimento com indústrias frigoríficas e distribuidores de carne orgânica, ou seja, a transação é governada da maneira eficiente para efetividade das ações dentro do sistema, s $>0$, condição necessária e suficiente para a transação sustentável e, consequentemente, SAG's sustentáveis. Essa lógica pode ser declarada na hipótese $\mathbf{H}_{1}$ : Transações que envolvem ativos específicos dedicados à sustentabilidade necessitam de salvaguardas para sua operacionalização.

Quanto à análise Macroanalítica, os casos expuseram a importância das instituições e organizações como deslocadoras dos custos de transação inerentes aos ativos específicos dedicados à sustentabilidade afetando a capacidade de coordenação do sistema rumo à sustentabilidade. Essa consideração sugere a hipótese $\mathrm{H}_{2}$ : Instituições e organizações são capazes de afetar a capacidade de coordenação para sustentabilidade em Sistemas Agroindustriais.

O estudo não apresentou nenhum caso de ausência de ativos específicos dedicados à sustentabilidade $\left(\mathrm{K}_{\mathrm{s}}\right.$ $=0$ ), pois não faria sentido estudá-los em se tratando de sustentabilidade da carne bovina. Acredita-se que agentes que não se preocupam com essas questões, como na produção convencional, não fazem investimentos em sustentabilidade, e provavelmente a carne é negociada como commoditty, conforme nó "A" do modelo, encontrando no mercado incentivo suficiente para a transação. 


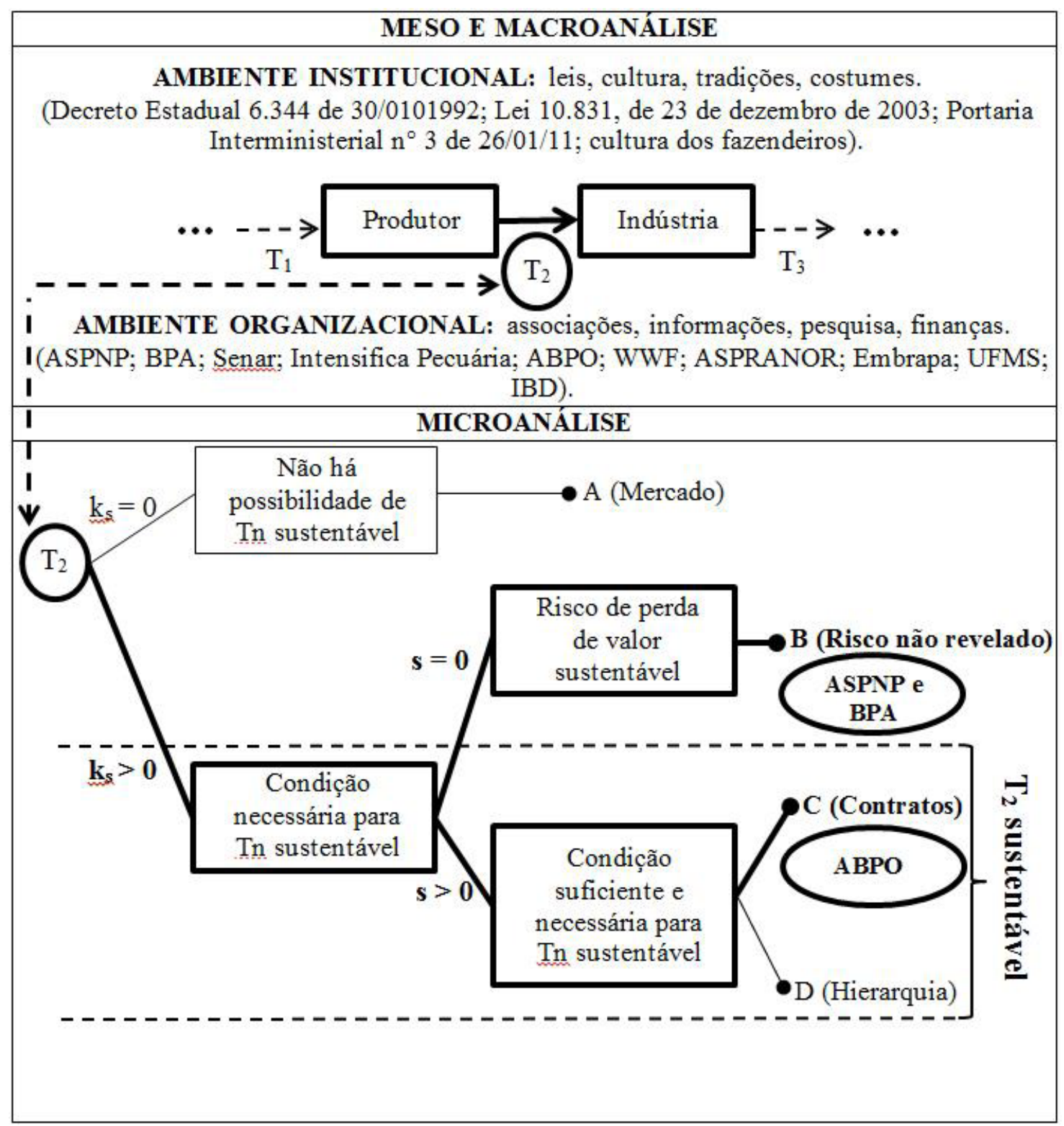

FIGURA 7 - Análise geral dos casos com vistas ao modelo analítico de SAG's sustentáveis Fonte: elaborado pelo autor

\section{CONSIDERAÇÕES FINAIS}

No artigo, discute-se um modelo analítico para Sistemas Agroindustriais Sustentáveis, baseado nas prerrogativas da Nova Economia Institucional, especificamente nos aportes da Economia dos Custos de Transação. Também procurou identificar como está sendo tratada a questão da sustentabilidade no SAG da carne bovina de Mato Grosso do Sul, por meio de casos que declaradamente têm ações em relação a essa questão. Logo, foi declarado um modelo de análise para SAG's sustentáveis e um estudo para a replicação teórica nos casos.

Nesse sentido, uma transação sustentável, envolve ativos específicos dedicados à sustentabilidade que, 
ao mesmo tempo, possuam salvaguardas (contratos ou hierarquia) como formas de governança capazes de operacionalizar a sustentabilidade nos Sistemas Agroindustriais. Também se apurou que as instituições e organizações são capazes de afetar a capacidade de coordenação das transações sustentáveis, deslocando os custos de transação inerentes aos ativos específicos, afetando o sistema ruma à sustentabilidade.

A pesquisa também contribui para a gestão das organizações e dos sistemas, mostrando um caminho para melhor operacionalidade dos aspectos relacionados ao tema da sustentabilidade. Sugere-se aos proprietários que investem em sustentabilidade, consequentemente às associações estudadas e ao programa BPA, que avaliem a forma de governança dos ativos sustentáveis, a fim de assegurarem a captura do valor gerado e a continuidade das ações.

Para políticas públicas o estudo mostrou a capacidade das instituições e organizações, como leis, regulamentações, decretos e portaria, associações, institutos de pesquisa, organizações de financiamento, afetar sistemas produtivos na busca por sustentabilidade.

Contudo, há limitações no estudo. Não foram investigadas as outras transações do SAG da carne bovina (T1, T3 e T4) pela restrição de tempo de pesquisa, deixando a análise mesoanalítica para outra oportunidade. Outra ressalva do estudo é a incapacidade de se realizar testes e generalizações estatísticas, capazes de avaliar as hipóteses declaradas, correndo-se o risco de não contemplação de aspectos relevantes. Por outro lado, essas limitações podem ser entendidas como futura agenda de pesquisa. Sugere-se a replicação do estudo para outros SAG's ou, até mesmo, outros sistemas produtivos além dos agroalimentares.

\section{REFERÊNCIAS}

ABPO - Associação Brasileira de Pecuária Orgânica. Quem somos. Disponível em: $<$ http://www.abpopantanalorganico. com.br/pt/quem-somos>. Acesso em: 12 Jun 2013.

ALMEIDA, A. J. DE; BUnGenstAB, D. J.; BUnGenstAB, E. J. O novilho precoce de Mato Grosso do Sul: um moderno sistema de produção de carne. Campo Grande - MS: UFMS, 1996.

ARAÚJO, G. C.; MENDONÇA, P.S.M. Análise do processo de implantação das normas de sustentabilidade empresarial: um estudo de caso em uma agroindústria frigorífica de bovinos. Revista de Administração Mackenzie, v. 10, n. 2, mar./abr, 2009.

AZEVEDO, PAULO FURQUIM DE. A Nova Economia Institucional - Antecedentes. In: FARINA, E. M. M. Q.; AZEVEDO, P. F.; SAES, Maria S. M. Competitividade: mercado, estado e organizações. São Paulo: Editora Singular, 1997.

BARBIERI, J. C; CAJAZEIRA, J. E. R. Responsabilidade Social Empresarial e Empresa Sustentável: da teoria à prática. São Paulo: Saraiva, 2009.

BATALHA, M. O; SILVA, A. L. Gestão agroindustrial. 3. ed. 6. reimp. Grupo de estudos e pesquisas agroindustriais (GEPAI), São Paulo: Atlas, pp. 1-62, 2012.

BRASIL. Portaria Interministerial MAPA/MA/MET $\mathrm{n}^{\circ}$ 36 de 26 de Janeiro de 2011. Diário Oficial da União (DOU), 26 de Janeiro, 2011.

BULGACOV, S. Estudos comparativos e de caso de organizações de estratégia. Organizações \& Sociedade, v.5, n.11, p. 53-76, 1998.

CALEMAN, S. M. Q. et al. Framing sustainability in agro food chains: from mysticism to actual practice. Revista de Economia e Administração, v. 12, n. 2, pp. 198-216, 2013.

CARIDADE, A, V. Relação entre finanças corporativas e sustentabilidade: um estudo de caso ligado à pecuária amazônica. Revista de finanças aplicadas, 2011.

COSTA, A. A. V. et al. Alguns indicadores/índices para a sustentabilidade da produção bovina. Revista de Ciências Agrárias, v. 31, n. 1, 2008.

CRESWELL, J. W. Projeto de pesquisa: métodos qualitativo, quantitativo e misto. Trad. Magda Lopes, ed. 3, Porto Alegre: Artmed, 2010.

CUNHA, C. F. da et al. Percepção sobre atributos de sustentabilidade em um varejo supermercadista. Revista de Administração de Empresas, v. 51, n. 6, pp. 542-552, 2011.

EISENHARDT, K. M. Agency Theory: An Assessment and Review. The Academy of Management Review, v. 14, n. 1, p. 57-74, 1989. 
ELKINGTON, J. Canibais com garfo e faca. Trad. Patricia Martins Ramalho. São Paulo: Makron books, 2001.

DAVIS, H. J; GOLDBERG, RAY A. A concept of agribusiness. Division of Research. Graduate School of Business Administration. Harvard University, Boston, 1957.

FABER, N.; JONAS, R.; ENGELEN, J. The sustainability of "sustainability": a study into the conceptual foundations of the notion of "sustainability". Journal of Environmental Assessment Policy and Management, v. 7, n. 1. pp.1-33, 2005.

FARAHNAZ, P. K. et al. Identifying Sustainability Issues for Soymeal and Beef Production Chains. Journal of agricultural and environmental ethics, v. 27, n. 6, pp. 949-965, 2014.

FARINA, E. M. M. Q. Abordagem sistêmica dos negócios agroindustriais e a economia de custos de transação. In: FARINA, E. M. M. Q; AZEVEDO, P. F. de; SAES, M. S. M. Competitividade: mercado, estado e organizações. São Paulo: Editora Singular, 1997.

GOLDBERG, R. A. Agribusiness coordination: A systems approach to the wheat, spybean, and florida Orange economies. Division of Research. Graduate School of Business and Administration. Harvard University, Boston, 1968.

HAFLA, Aimee N. et al. Sustainability of US Organic Beef and Dairy Production Systems: Soil, Plant and Cattle Interactions. Sustainabililty, v. 5, n. 7, pp. 3009-3034, 2013.

IKERD, J. E. The need for a systems approach to sustainable agriculture. Agriculture, Ecosystems and Environment, v. 46, p. 147-160, Amsterdam, 1993.

KIDD, C. V. The evolution of sustainability. Journal of Agricultural and Environmental Ethics, v. 5, n.1, p.126, 1992.

MACEDO, M. C. M. Integração lavoura e pecuária: o estado da arte e inovações tecnológicas. Revista brasileira de zootecnia, v. 38, pp. 133-146, 2009.

MARREWIJK, M. Concepts and definitions of CSR and corporate sustainability: between agency and communion. Journal of Business Ethics, v. 44. n. 2-3. pp. 95-105, 2003.
NORTH, D. C. Institutions, institutional change and economic performance. Cambridge University Press, 1990.

NORTH, D. C. Institutions. The journal of economic perspectives, v.5, n.1, pp. 97-112, 1991.

SPECHT, Leandro et al. Avaliação da sustentabilidade da pecuária de corte extensiva tradicional do pantanal sul-mato-grossense através da metodologia emergética. Revista Brasileira de Agroecologia, v. 7, n. 3, pp. 16$25,2012$.

STEINER, J. L. et al. Knowledge and tools to enhance resilience of beef grazing systems for sustainable animal protein production. Annals of the New York Academy of Sciences, v. 1328, pp. 10-17, 2014.

WILLIAMSON, O. E. The Economic Institutions of Capitalism: Firms, Markets, Relational Contracts. New York: The Free Press, 1985.

WILLIAMSON, O. E. Comparative Economic Organization: the analysis of discrete structural alternatives. Administrative Science Quarterly, v. 36, pp. 269-296, 1991.

WILLIAMSON, O. E. The New Institutional Economics: taking stock, looking ahead. Journal of Economic Literature, v. 38, pp. 595-613, 2000.

WILliAMSON, O. E. The Theory of the Firm as Governance Structure: From Choice to Contract. Journal of Economic Perspectives, v. 16, n. 3, pp. 171-195, 2002.

WWF-BRASIL. Bacia do Alto Paraguai cobertura vegetal - Monitoramento das alterações da cobertura vegetal e uso do solo na Bacia do Alto Paraguai porção brasileira (período de análise: 2008 a 2010), pesquisa técnica, Braília-DF, 2012.

YIN, R. K. Estudo de caso: planejamento e métodos. Trad. Ana Thorell, ed. 4, Porto Alegre: Bookman, 2010.

ZYLBERSZTAJN, D. Estruturas de governança e coordenação do agribusiness: uma aplicação da nova economia das instituições. São Paulo, Tese (Livre Docência), Departamento de Administração, Faculdade de Economia, Administração e Contabilidade da Universidade de São Paulo, 1995. 